\title{
Medicine and the structure of knowledge: Contextualising medical knowledge to meet local health needs
}

\author{
Anand Zachariah ${ }^{1}$ \\ Journal of the Ceylon College of Physicians, 2019, 50, 10-17
}

\begin{abstract}
'What is appropriate knowledge, practice and education to address our health care problems?'
The thesis of my talk is that context has to be the central aligning feature in our knowledge, practice and education to address our health problems. We require contextual knowledge, a contextual practice and a contextual education.
\end{abstract}

This oration will be divided into three parts: Contextual knowledge, contextual practical and contextual education.

\section{Contextual knowledge}

\section{Case of Hina Begum}

I would like to begin my talk with the story of Hina Begum, a domestic worker living in the slums of the city of Hyderabad who presents with chronic headache, feeling weak, tired and dizzy. Her symptoms are closely linked to overwork, having to go to several houses, and worrying about her daughter, whose husband has a neurodegenerative problem, and her children. She takes a local balm to relieve her headache and when she cannot manage, she goes to a nearby doctor who gives her a glucose infusion, so that she can go back to work the next day.

This case may sound familiar to you. The knowledge of medicine was not adequate to address the life circumstances of this patient. Modern medicine does not have a prescription adequate to the case of Hina Begum. If she were to come to CMC, she would undergo a battery of tests and be prescribed antidepressants, vitamins and calcium and be advised to rest. This would be too expensive for her and she would lose her wages. Instead she goes to a local doctor, who may be a non-formal practitioner but one who understands her problem. The knowledge of medicine is not commensurate to the life circum-stances of Hina Begum. Perhaps it is the non-formal doctor who is able to provide relevant medical care.

\footnotetext{
${ }^{1}$ Department of Medicine, Christian Medical College, Vellore, India.

E-mail: zachariah@cmcvellore.ac.in
}

The focus of this talk is to understand why this problem has arisen - i.e., the mismatch between knowledge and context.

\section{The birth of the clinico-pathological method}

The painting by Théobald Chartran (1816) is a portrait of Laennec auscultating a patient with his new device, the stethoscope, and dictating his findings to the nearby nurse in the presence of his students. The patient was an emaciated consumptive patient. Laennec was known to perform post-mortems on the patients who died. From his objective clinical records, he was able to relate symptoms and signs in life to post-mortem pathological findings. In other words, Laennec was known for a clinical method which was able to diagnose in life, what would otherwise have been evident only at death. The mode of the clinicopathological thinking that this painting represents is one of the most important frames of medical knowledge. This is also a framing moment in the formation of that knowledge.

The birth of the clinical-pathological method also marks another important shift. With the clinical method of percussion and auscultation, it was possible to diagnose disease based on clinical examination without knowing and understanding the patient. The form of medical knowledge that was born objectified the symptoms and signs, and made it possible to diagnose disease without knowing who the patient was and their experience of illness. The separation of medical knowledge from the experience of the sick patient is part of the same framing process that occurred with the birth of the clinic-pathological method. 
Michel Foucault, a well-known historian of medical knowledge, used the genealogical method to study the birth of medicine in Europe in the $18^{\text {th }}$ and $19^{\text {th }}$ centuries. In 'Birth of the Clinic', he showed that medicine was born in a governmental format' ${ }^{1}$. The task of medicine was not to address the sick patient, as there was very little treatment available at that time. The task of medicine was to govern the population and give economic and security strength to the emerging nations in Europe. Medicine was engaged in census, in cordoning of cities with areas for the rich and poor, dealing with epidemics and quarantine. It was not that medicine was influenced by the task of government, rather that medical knowledge itself developed as an administrative and governmental form of knowledge. From its birth, the formation of medical knowledge was not to answer the call of the sick person, but rather to give strength and political power to the newly-forming nations.

\section{Take off of Western Medicine}

Michel Foucault further argued that an important shift occurred in the structure of medical knowledge following World War II. He referred to this shift as the 'take off' of modern medicine? ${ }^{2}$.

England was suffering from an economic crisis after the War. It was during this period of great difficulty that Britain took the unusual step of reviving the economy, by executing the Beveridge Plan to create a National Health System that could provide medical care to all its citizens. For the first time in history, Britain articulated the right to health. In creating the national health system, it ear-marked a significant proportion of its national budget to health care and medical research. All countries in Europe followed suit in the creation of welfare states across Europe. Suddenly as never before, financial support in macroeconomic terms became available for the establishment of hospitals and medical research. Parallel to these events there occurred the growth of large hospitals, technologies in medicine, development of medical specialisations in both Europe and the United States. The medical knowledge that evolved in this period was for their health system and for their health problems.

\section{Transplantation of tertiary care knowledge into India}

In India we have witnessed in the post-1960's period the parallel growth of tertiary hospitals and specialisations of Western Medicine. An argument that I will be making is that when the knowledge that developed in the West is transplanted into India and other countries like ours, there occurs a mismatch between the setting of origin and the setting of application of that knowledge, which leads to problems of both appropriateness and $\operatorname{cost}^{3}$.

I have tried to paint some broad historical strokes of the problem of formation of medical knowledge. I will try to give you a more concrete example with the case of the knowledge of hypertension and ischaemic heart disease.

\section{Relation of the normal and pathological in western medical thought}

Georges Canguilheim, another important philosopher of medical knowledge, stated that every concept of disease in Western Medicine is derived from a therapeutic desire to cure sickness ${ }^{4}$. He made the case that 'pathology' and 'normal' were two different entities and that it was the study and description of disease/pathology that enabled the statement of the 'normal'. He argued that it was from the clinical description of diabetes that the understanding of glucose metabolism emerged, and from the description of Addison's disease that the understanding of the role of the adrenal gland in blood pressure emerged. His argument was that pathology was central to the formation of all medical knowledge, both the normal and the abnormal. Using Canguilheim's mode of analysis, I would like to investigate the change in the representation of hypertension and the relationship of the normal and abnormal with the take off of modern medicine.

\section{Change in the representation of hypertension}

Through the $20^{\text {th }}$ century, we observe a change in the representation of hypertension from a clinicopathological representation in the late 1800's to a virtual or epidemiological representation from the early 1970's. In 1874, an Anglo-Indian doctor in England, Mohamed, used the term 'hypertension' for the first time to describe a pre-albuminuric form of Bright's disease. Bright's disease was a clinical syndrome noted in the early $19^{\text {th }}$ century associated with stiffening of the pulse, heart failure, oliguria and albuminuria associated with post-mortem findings of contracted kidneys. Mohamed used the term hypertension to describe cases where there was the clinical syndrome of Bright's disease, but no albuminuria or contracted kidney. The term hypertension derives from 'hyper' and 'tension', meaning an increased tension of the vessel wall. In fact, the description of hypertension preceded the discovery of the blood pressure apparatus. The important point to note here is that at its birth, hypertension was not a measurement, but rather a clinical 
syndrome. It was the clinical syndrome of heart failure that spurred the development of the measurement and study of blood pressure.

In the 1950's, there was controversy about the significance of high blood pressure (BP). It was thought that high BP without artery disease was a normal compensatory mechanism (or essential hypertension) and high BP associated with atherosclerosis was a pathological disease. In fact, Osler said that physicians treating high blood pressure were treating the 'blood pressure apparatus' rather than the patient. At this time in the 1950s, we must remember that the treatments available for hypertension were mainly parenteral drugs with major side effects.

There were two studies that changed this view of hypertension:

1. The Framingham Study of risk factors for cardiovascular mortality.

2. A Veteran Administration (VA) trial of diuretics in the treatment of hypertension.

\section{The Framingham Study}

President Roosevelt died shortly before the end of World War II of a hypertensive intracerebral bleed. His medical records when reviewed showed that he had very high blood pressure that was ignored despite being symptomatic. Following his death, President Truman signed the order for the creation of the National Heart Institute with a budget to conduct a study to determine the cause of heart attacks. The Framingham Study had already been initiated in the town of Framingham, as a traditional community prevention programme involving the local community. In performing the study, the National Heart Institute made several significant changes in the Framingham Study methodology:

1. The removal of factors which could not be objectively measured: diet, physical activity, stress.

2. The use of multi-variate statistics: this was the first time that multi-variate statistics were used in the study of chronic disease.

The study results showed for the first time that several factors such as high BP, smoking, overweight and cholesterol were associated with heart attacks. The question was whether these associations indicated cause-and-effect relationships. Despite reservations from statisticians, the clinicians used the term 'risk factors' in the early publications to suggest an etiological association between these factors and heart attacks, even before there was actual proof. The risk factor concept caught the imagination of the medical community and the public as a new way of conceptualising heart disease in a predictable manner ${ }^{5}$.

\section{Merck Sharp and Dohme, Diuri ${ }^{\circledR}$ and the VA trial}

While the VA trial was important in demonstrating the benefit of anti-hypertensive drugs, it would not have occurred without the discovery, research and promotion of Diuri ${ }^{\circledR}$ (trade name for hydrochlorthiazide) by Merck Sharp and Dohme (MSD) ${ }^{6}$. While investigating Diuril for the treatment of heart failure, they found that it caused a pronounced fall in BP. They quickly reworked their research and marketing strategy to show that Diuril was an effective and safe anti-hypertensive agent. They promoted Diuril through company salesmen, publications in popular magazines and journals, and encouraged its widespread use for asymptomatic hypertension with physicians and the public even before evidence had accumulated that it was efficacious. The controversy about the rationality of treatment of asymptomatic hypertension led to the setting up of the clinical trial by VA with the informal support of MSD, which supplied the drug.

The VA trial showed that treatment of patients with elevated BP led to a fall in deaths due to heart failure, strokes and heart attacks. Its publication led to the formation of the Joint National Committee (JNC) for setting up guidelines for the diagnosis and treatment of hypertension. The committee for the first time recommended a clear-cut blood pressure level for the diagnosis of hypertension. The new definition completed the shift in representation of hypertension from a pathological and clinical entity to an epidemiological concept - an important shift in the structure of knowledge.

Although the VA trial was important in the new definition of hypertension, this would not have occurred without MSD's active research and promotion strategy.

\section{The new and malleable concept of risk}

An examination of the definition of 'risk factors' in the last decades of the $20^{\text {th }}$ century shows that there have been falling cut-offs for the initiation of drug treatment for high blood pressure, diabetes and hypercholesterolemia, and formation of new categories such as 'pre-diabetes' and 'pre-hypertension' [or in other words, 'pre-risk categories'] ${ }^{5}$. Disease becomes a malleable concept with a blurring of the distinction between 'disease' and 'normal'. This is because 'risk' itself is a malleable statistical concept. It is not disease in terms of symptoms or signs, but a physiological abnormality that predicts risk of disease in the future. It is the availability of treatments which reduce the 
risk of events in the future that has led to the formation of these new categories. 'Risk' itself becomes a disease, a new form of normality. Today large proportions of the population that have abnormal risk factors are required to be treated.

The risk factor concept has also led to a new style of public health in the United States, not through traditional public health measures, but through drug treatment for 'risk factors' implemented through America's private health system.

Parallel to these developments, the last decades of the $20^{\text {th }}$ century have witnessed the rapid evolution of evidence-based treatments for heart attacks, thrombolysis, stents, beta blockers, ACE inhibitors and antiplatelets. These randomised controlled trials were initially funded primarily by academic research organisations. As the size, complexity and cost of RCT's increased, it was not possible for governments and philanthropic organisations to support the cost of drug research. Progressively the majority of RCTs shifted to becoming sponsored or supported by pharmaceutical organisations.

\section{The new structure of medical knowledge: Industry-driven medicine}

The historical events that I have described have led to a new structure of medical knowledge that is industry-driven. From historical studies, we understand that the pharmaceutical industry has not only researched drugs, but has actively developing marketing strategies at the same time to increase the indications for use, drug sales and market share. Therefore the disease and therapeutic concepts that have evolved from this style of research are not necessarily only for the ethical benefit of the patient, but are also answerable to the call of the company shareholders.

When an average middle class patient is admitted with a heart attack in a corporate hospital in India, the cost of health care forces the family to go into debt. The structure of knowledge is not accountable to the sick person. There is a mismatch between knowledge and context.

What I have argued so far is that there is a new structure of knowledge in the last half of the $20^{\text {th }}$ century, which is statistical in its nature, where the concept of disease has widened to include the concept of 'risk' and is closely wedded in its structure to the pharmaceutical industry. For all these reasons, the structure of the concept of disease has problems of accountability to the patient.

\section{Are there other structures of knowledge which are accountable?}

\section{HIV/AIDS}

Patient care movements across the world have been important in the development of Highly Active Anti-Retroviral Therapy (HAART) for Human Immunodeficiency Virus (HIV) infection, and also in addressing the divide between countries that had and did not have HAART. Peoples' movements forced the WHO to convert tertiary care guidelines to those that could be delivered in primary care. They also forced pharmaceutical companies to reduce their drug prices. Today, HAART is available in every district hospital in India and to each and every citizen who needs it. This is indeed a creditable achievement for a Western science that was governed by the same pharmaceutical interests that have controlled cardiovascular research?.

\section{Pesticide poisoning in Sri Lanka}

In your country we have witnessed the dramatic decline of suicide mortality as a consequence of the banning of highly hazardous pesticides. This ban has been based on a body of research that has documented the 'local disease of pesticide poisoning'. This is a remarkable achievement in the field of toxicology - a contextually-relevant and ethical knowledge, accountable to the people of Sri Lanka.

\section{Conclusion}

Would knowledge that does not have an ethical responsibility to the patient be ethical? Ethical knowledge has to be one that has responsibility to the patient, to their family and their community. In other words, ethical knowledge has to be contextual. The task for the academic communities in our countries is to develop a knowledge base that has accountability to our local health problems and local communities.

\section{Contextual practice of medicine}

We usually view practice as the simple application by the doctor of evidence-based knowledge or universal knowledge to the individual patient. There are many gaps and constraints in the application of universal knowledge to an individual setting. A concept derived from one location (universal object) cannot just be applied in the local setting. There are problems of appropriateness and cost. The doctor has to have an understanding of local disease and the social background of the patient. He or she has to rework it, adjust the received knowledge and modify it in a responsible way to meet the requirement of the individual situation. 
The scope of practice is exemplified in the Venn diagram below. Practice involves three types of knowledge: theoretical knowledge, practical knowledge and social knowledge. Practice involves applying theoretical knowledge in relation to the individual patient and their social background and preferences (social knowledge) and based on the doctor's own experience and knowledge of the local disease (practical knowledge). Doctors are constantly, consciously and unconsciously doing this, bringing these three knowledges together in the performative practice of medicine. The performance of the practice of medicine is a complex and demanding task.

\section{Contextual practice}

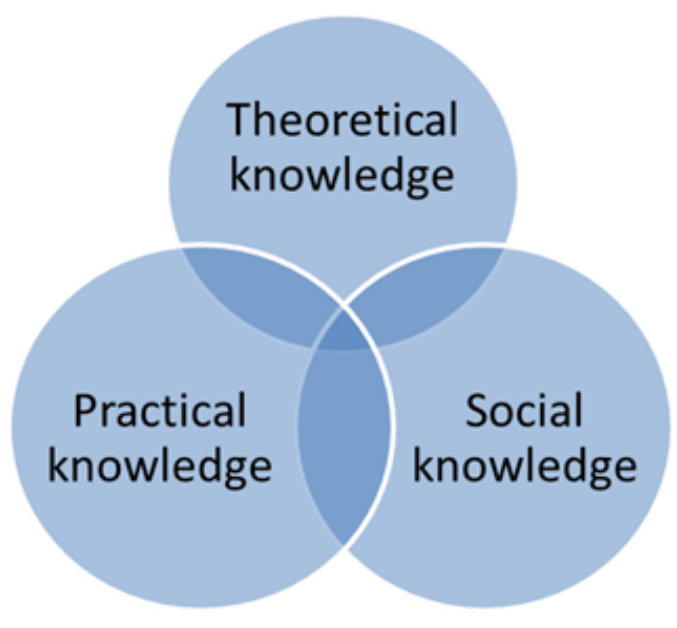

\section{Practice in the ICU and negotiation of knowledge}

I will be using a case study of the 'practice in the ICU' to show the negotiation of these three knowledges ${ }^{8}$. I am using the word 'negotiation' to refer to the dialogue that takes place between the participants: the doctor, patient and relatives. It is through this dialogue that negotiation takes place between their different knowledge perspectives.

\section{Case study}

$\mathrm{N}$ was a case of severe organophosphate (OP) poisoning, which required ventilation in the Intensive Care Unit (ICU). One week after hospitalisation he was in deep coma, with the absence of motor response or eye movement and with sluggish brain stem reflexes despite withdrawal of sedation. A diagnosis of hypoxic encephalopathy was considered, and discussions initiated regarding withdrawal of therapy because of socio-economic reasons.
Doctor's narration of the rounds on the $8^{\text {th }}$ day:

"N's failure to wake up was distinctively unusual and disturbing. We repeated the clinical examination and concurred with the earlier assessments. We called the patient's sister in, to explain the possibility that he may not recover. She requested to come in and see him which we refused, as it was not visiting hours and in any case he was comatose. On her persistence we agreed with reluctance. She came to the bedside and called out to him, 'brother open your eyes, it's me sister'. Initially there was no response, but she kept persisting. Then slowly there was a flicker of movement. He then consistently opened and closed his eyes to her request. For us this was some kind of miracle. A person whom we considered to be brain dead was actually alive and just severely paralysed. By the following day the patient's motor power started to recover and he was weaned off the ventilator."

\section{Analysis of the negotiation}

Medical perspective: N's failure to wake up could indicate irreversible brain damage, and protocols were initiated towards this.

Sister's perspective: She wanted her brother to survive and doubted our diagnosis. She forced her way into the ICU.

Negotiation: By communicating with her brother, she could show us that our assessments were not correct. He was just severely paralysed.

\section{Outcome of this negotiation:}

Improved clinical outcome: $\mathrm{N}$ was able to survive and go home alive.

New practical knowledge: The description of a severe form of the intermediate syndrome which mimics brain death. This has helped in the management of subsequent patients.

In this study we documented several communication acts that made a substantial difference to the outcome of medical management. They exceeded standard evidence-based guidelines. They occurred in the unpredictable dynamic of the ICU, between the medical team, patient and their family. The negotiation of knowledge between the perspectives of patient, sister and doctor led to something greater than the standard of treatment. They brought responses that substantively altered the quality and outcome of medical care and enabled the creation of new practical knowledge. 


\section{Contextual medical education}

\section{Structure of the problem of medical education}

Today the majority of medical education is occurring in medical college hospitals where students learn tertiary care medicine from role model teachers who are specialists. When graduates complete their training they are ill-equipped to work in primary and secondary care, where they require practical knowledge and social knowledge. There is a mismatch between the training they have received in medical college and the requirements for practice at primary and secondary level. Therefore, they prefer to work as specialists in cities or migrate abroad. The situation is being made worse by the current forces of global education, which are encouraging standardisation of medical education, competency-based curricula and training towards a global doctor.

\section{The CMC model of MBBS medical education}

The Christian Medical College (CMC) was started as a women's missionary medical college by Dr. Ida Sophia Scudder to address the needs of women dying in child labour for lack of women-doctors. Central in the philosophy of our college has been the meeting of health needs through training and education. Over a period of 100 years, the CMC has incrementally developed an approach to education that reflects its philosophy and mission of training competent and committed health professionals who can work at primary and secondary levels in areas of need.

The CMC's health system involves the medical college hospital and three secondary hospitals, which provide primary and secondary care to a community of 300,000 people in the urban town and surrounding rural areas. We are also linked to 200 mission hospitals across the country, many of them in rural and remote areas. The CMC uses the entire health system for training in all its courses.

Some of the principles of our education are:

1. Community exposure:

This occurs through the community health training, family medicine training and secondary hospital postings. In the community health training, students live in the community and learn from the people, study local problems and design interventions to address these problems. In the Family Medicine training they learn the principles of primary care. In the secondary hospital postings students are sent in small groups to hospitals in remote parts of the country to learn the principles of secondary care. This exposure is important in preparing students for rural service.

2. Practical clinical training:

Students learn the practice of medicine through clerkships where they participate in medical care as members of the team in all the important clinical subjects. They develop procedural skills in the skills lab to prepare them for internship and work in rural hospitals.

\section{Service obligation:}

All students have a 2-year service obligation period, where they work in rural secondary hospitals. This period is supported by a distance education course in Family Medicine.

An educational idea that has emerged from the CMC model is that of the contextual curriculum. A contextual curriculum emphasises the importance of social and health care context in the process of curriculum design ${ }^{9}$. It is premised on the need for education to be aligned to the health care needs of the community. It is based on the belief that medical colleges should work with the health services towards improving health and health care. In this centenary year, we are using the contextual curriculum model to review our curriculum and to strengthen it.

The contextual curriculum involves four important aspects (See Diagram in next page):

1. Prioritising health problems:

Having a clear vision of the doctor that we want to train, and prioritising local health problems in the curriculum.

2. Contextual knowledge of medicine:

Learning local epidemiology, the differences in clinical profile, cost-effective investigation and management.

3. Contextual practice of medicine:

Being involved in the practice of medicine, managing common problems, communicating with the patient and family, addressing issues of cost, access, social and family issues.

4. Learning within the community and contributing to the health care of the community:

Learning at the level of primary and secondary care from role model teachers, and contributing to the health care of communities. 


\section{CONTEXTUAL CURRICULUM - CONCEPTUAL FRAMEWORK}

\section{Assessment}

Planning assessment in relation to all the above Aligning assessment to the goals of the curriculum and competency list
Learning practice of medicine within the community setting primary and secondary care, in mission hospitals

Role model teachers - mission hospital doctors, public health workers

Understanding the perspective of the patient and family

Contributing to improvement of health and health care of families and communities
Vision

Competencies

Syllabus Content

Teaching and learning resources

Planning teaching and learning experience

\section{Learning}

and contributing to health care of the community
1. Prioritising health problems

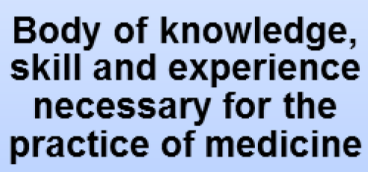

2. Contextual knowledge, appropriate to the local setting

Epidemiology

Causation

Clinical features

Scientific base and understanding research

Laboratory tests

3. Contextual practice of medicine
Diagnosis, management and prevention

Implications of differences between settings

Being involved in the practice of medicine

Learning by managing common problems in outpatient and emergency setting

Performing essential procedures competently

Being involved in communicating with patient and family

Addressing issues of cost, access, social, cultural and health system issues in the process of care 


\section{Conclusion}

We are all involved in this task of moving our knowledge, practice and education towards our local situation and context. In using the terms contextual knowledge, contextual practice and contextual education, what I am making is a more conscious articulation of these moves: A move away from the universal knowledge, towards the development of a locally relevant knowledge base; a move away from practice as the application of a set of evidence-based guidelines towards a deliberate practice as a responsible negotiation between medical knowledge, practical experience and the social world of our patients; a move away from education as a globally homogenous process, towards education as a formation of change agents who can work towards providing appropriate health care for our people. I hope that these terms may be helpful in enabling us to think more carefully about these moves.

I would like to draw some reflections to conclude this oration. Amitav Ghosh, the well-known Indian novelist, writes in his book 'The Great Derangement' about the inability of the modern novel and modern thinking to grapple with the seriousness and gravity of the impact of development on climate change ${ }^{10}$. The recent Kerala floods which displaced half a million people, appears as proof that his prophecy has come true.

In modern medicine too, I would argue that we are in crisis, which reflects a great derangement in medicine; the inability to comprehend the impact of our development thinking on modern medicine; a structure of medical knowledge which is increasing the costs of health care, widening inequality in access and causing more and more iatrogenicity; formats of medicine that are unsustainable and increasingly unaccountable to the living world of the sick person.

In this context we need to ask the question: What trajectory of medicine do we need for our countries? At this point in the history of medicine, such a question is becoming difficult to articulate, with the increasingly standardised formats, and firming up of the frame of biomedical knowledge. The fact that the Ceylon College of Physicians has requested an oration on the structure of medical knowledge indicates your concern with the present structure of knowledge.

Your country has so many strengths, the strong public health system, health status and the track record of tackling priority health problems such as poisoning and malaria. You have succeeded where India has abysmally failed. In India we are asking the question, what enabled Sri Lanka to succeed.
And at this point in the history of medicine, it is important in our respective countries to encourage a tradition of critical study of medicine in relation to our health problems. We need to develop our philosophers and theoreticians, such as Michel Foucault and Georges Canguilheim, to help us think about the philosophy of medical knowledge. We need to develop a tradition of critical social science research in medicine.

It is clear that we need to articulate the contextual in relation to our knowledge, our practice and our education. This has been the thesis of my talk. The articulation can be the beginning of a new trajectory for medicine that has the possibility of hope to provide a democratic and accountable health care for our peoples.

\section{References}

1. Michel Foucault. The Birth of the Clinic: an archaeology of medical perception. Originally published in 1963 as Naissance de la Clinique (French). Originally published in English language in 1973 by Tavistock Publications Limited.

2. Michel Foucault (1978). The crises of medicine or the crises of anti-medicine. In Foucault studies, No. 1, 2004 (talk originally delivered in 1978), 5-19.

3. Anand Zachariah, R. Srivatsan and Susie Tharu. Introduction: the Dilemmas of Medical Culture Today. In Towards a Critical Medical Practice 2010; 1-34. Orient Backswan, Hyderabad.

4. Georges Canguilhem. The Normal and the Pathological. Originally published in 1966 as Le normal et le pathologique (French). Originally published in English language in 1978 by D. Reidel Publishing Company, Dordrecht, Holland.

5. Robert Aronowitz (2015). Risky Medicine: our quest to cure fear and uncertainty. The University of Chicago Press, Chicago.

6. Jeremy A Greene. Releasing the Flood waters: Diuril and the reshaping of hypertension. Bulletin of the History of Medicine 2005; 79 : 749-94.

7. Anand Zachariah. Peoples' struggles producing a curative public health for AIDS. In: Towards a Critical Medical Practice, pp. 299-310. Orient Backswan, Hyderabad.

8. Anand Zachariah (2010). Practice in the ICU: the case of organophosphate poisoning. In: Towards a Critical Medical Practice 2010; 285-98. Orient Backswan, Hyderabad.

9. Janet $\mathrm{G}$, Abdelrahman $\mathrm{YH}$, Zachariah $\mathrm{A}$. Curriculum design in context. In: Oxford Textbook of Medical Education, Keiran Walsh (ed.), 2013; 13-24, Oxford University Press, Oxford.

10. Amitav Ghosh (2016). The Great Derangement: climate change and the unthinkable. Published by Allen Lane by Penguin Books India. 